\title{
Intrauterine Fetal Death
}

National Cancer Institute

\section{Source}

National Cancer Institute. Intrauterine Fetal Death. NCI Thesaurus. Code C50620.

Death of a fetus after 10 weeks gestation. 